\title{
Factors Affecting Cervical Cancer Screening Practice Among Women Attending Gynecology Out - Patient Department at Mettu Karl Referral Hospital, South West, Ethiopia, 2019
}

Desalegn Nigatu ( $\nabla$ dessuko2013@gmail.com )

Mettu University https://orcid.org/0000-0003-1892-5581

Dessalegn nigatu Nigatu

Mettu University

Research Article

Keywords: cervical cancer screening, Ethiopia, associated factors

Posted Date: April 21st, 2021

DOI: https://doi.org/10.21203/rs.3.rs-446017/v1

License: (c) (i) This work is licensed under a Creative Commons Attribution 4.0 International License. Read Full License 


\section{Abstract}

Introduction : Globally, Cervical cancer is the greatest threat to women's health, which is the fifth cause of death accounting for all types of cancer deaths among women. Globally, 528000 new cases each year and the second most common in developing countries around 445,000 new cases develop cervical cancer each year. Cervical screening practice is the recommended for effective methods for prevention and early detection of cervical cancer. To increase the awareness of cervical cancer screening practice health education is pivotal in any prevention program aimed in reducing the overall prevalence of cervical cancer in the community.

Objective : To assess cervical cancer screening practice and associated factors among women attending gynecology out -patient department and maternal and child health at mettu karl referral Hospital, South west, Ethiopia, 2018.

Methods : Institutional based cross-sectional study was carried among 321 patients. Systematic random sampling was applied to select study subject and descriptive analysis were employed to describe the percentages and number distributions of the respondents for socio-demographic characteristics. The data was collected through interviewing of respondents and the data was entered EPI data version 4.2 and analyzed by using SPSSS version 20.Bivariate analysis was also used to see the association of independent with the dependent variable. Crude and adjusted odds ratios with the corresponding $95 \%$ confidence intervals were computed. A P-value less or equal to 0.05 was considered statistically significant in this study.

Result: In this study a total of 321 clients were participated in the study. The mean age was 35.79 with SD \pm 11.46 . The majority of participants 225(70.1\%) were not intended cervical cancer screening while $96(29.9 \%)$ were intended cervical screening respectively. Age $\geq 50(A O R=26.603 ; 95 \% \mathrm{Cl}=8.167,86.662)$,age between $40-49$ $(A O R=4.152,95 \% \mathrm{Cl}=1.630,10.576)$, had smoking $(\mathrm{AOR}=0.179 ; 95 \mathrm{Cl}=0.087,0.369)$, women's who had STD AOR=0.169; $95 \% \mathrm{Cl}=0.82,0.347)$, multiple sexual partner of the husband $(\mathrm{AOR}=1.221 ; 95 \% \mathrm{Cl}=0.687,2.200)$ and were used contraceptive $(A O R=0.172 ; 95 \% \mathrm{Cl}=0.070,0.422)$ were found to have strong association with cervical screening behaviors.

CONCLUSION AND RECOMMENDATIONS: According to this finding, the overall rate of those participants who had good screening for cervical cancer practice were about 29.9\%. Maternal age, using smoking, using contraceptives, presence of sexually transited disease, and having multiple sexual partner of the husband are predominantly stated factors associated with cervical screening practice.

\section{Introduction}

Globally, cervical cancer is always the greatest threat to women's health, it is the fifth cause of death accounting for all types of cancer deaths among women(1,2).Globally,528000 new cases cervical cancer each year and the second most common in developing countries around 445,000 new cases develop cervical cancer each year $(3,4)$.

The cervical cancer screening practice is to create access to early detection of cervical cancer and preventative therapy for millions of women worldwide(5). Global studies showed that early detection and treatment can prevent 75 per cent of cancers in developing countries, like other screening tests (3). Early detection through screening and treatment of pre-cancerous lesions remains the best possible protection against cervical cancer(6). Globally evidence shows that utilization of screening for prevention is very poor in developing countries. Unfortunately, it is estimated that one in every three U.S. adults is not getting screened as recommended(7) (5). In the US Screening for cervical cancer, which diagnosed in more than 12,990 women in 2016 , can both detect cancer at early stage(8) 
Prevalence and mortality rates are highest in developing countries; particularly sub-Saharan African nations estimated 528,000 new cases of cervical cancer. Cervical cancer commonly occurs in women aged ranged from 25-65 years(9). It is caused by infection by human papilloma viruses that transmitted from individuals to individuals by sexual intercourse which may infect the areas around the cervix, anus, mouth and throat(8). Of all the cancers, cervical cancer is the only one that has both an effective vaccine and screening program that can prevent disease and death(10). Cervical cancer, which is a malignant neoplasm, can be asymptomatic sometimes in early stages(11). The symptoms that can be seen normally in advanced stages are persistent pelvic pain, unexplained weight loss, unusual bleeding during periods, bleeding and pain after sexual intercourse(12) .

Cervical screening behavior is recommended effective methods for prevention and early detection of cervical cancer(13). However, awareness and knowledge about cervical screening behavior is lacking among lower socioeconomic status and high cost and low awareness were found to be the primary barriers to cervical cancer(14). Cervical cancer screening practice is recommended in Ethiopia, but due to the limited resources, awareness and knowledge is not yet easily available(15).

To increase the awareness of cervical cancer screening practice, health education is pivotal in any prevention program aimed in reducing the overall prevalence of cervical cancer in the community. For health education to be effective and have an impact and good outcomes on cervical screening behavior (8)

The incidence of cervical cancer screening practice varies greatly between developing and developed countries, where cervical cancer cases have been considerably abridged since the implementation of effective screening programs in developed countries(16). However, in developing countries, the burden from cervical cancer remains high because of the difficulty in implementing cytology-based screening programs (Pap smear, AVI)(17).

There are several barriers to the uptake of cervical cancer screening practice in low and middle-income countries(LMICs), which include low levels of knowledge of cervical cancer, limited awareness of prevention and early detection methods, fear of stigma associated with cancer diagnosis, concerns about spousal disapproval of screening, and concerns about violations of religious and cultural obligations of modesty during screening procedures(6). Even though there is no national Cancer registry in Ethiopia, a survey from federal Ministry of Health and Addis Ababa Cancer registry shows that 64,000 new cases of Cancer occur annually where Cervical and Breast Cancer constitute the significant majority of these cases. The problem rose from too little people's awareness about cancer, very limited treatment facilities and too little governments and other stakeholder's intervention(18).

Most of the women in the country visit health institution already with the advanced stage of cervical Cancer when they show up at the Hospitals. Cervical cancer is the leading cause of cancer mortality among Ethiopian women over the age of 30(19). On the other hand, the other study records show that 7600 Ethiopian women are diagnosed annually with cervical cancer and of these, 6000 die of the disease each year. Cervical cancer screening practice has been shown as the most effective way to decrease cancer mortality among all women (12).

In Ethiopia, only $0.6 \%$ of all women, $1.6 \%$ of urban and $0.4 \%$ of rural women aged $18-69 y$ rs screened every $3 y$ rs (20, 21).The major factors associated with cervical cancer screening practiceare inadequate knowledge about the disease process, and Pap smear testing and clients negative attitude towards the procedure $(14,22)$. Besides, poor knowledge about cervical cancer, and lack of awareness of available screening methods have been identified as the most important factors hindering the use of available cervical cancer screening practice services. Cervical cancer screening practice services are available in some areas of in Ethiopia(23), but screening is mostly conducted only when a woman seeks medical care for other reasons. Sometimes, screening is offered only if the woman presents with symptoms(24). Despite the evidence that universal screening is important, women without symptoms are not routinely 
screened in many locations in Ethiopia. In Ethiopia methods for screening are different in compared to high-resource countries(25).Gap identified in Ethiopia is most of the women have no awareness about cervical cancer screening practice. Little is known about the relative incidence of cervical cancer screening practice(4).

So this study is aimed to assess cervical screening practice among women attending gynecology outpatient department at Mettu Karl referral Hospital, South west, Ethiopia, 2019.

Therefore, this study will provide more evidence on the screening behavior of cervical cancer screening practice. The Finding of this study will give an insight to policy makers on cervical cancer screening practice and subsequent planning and implementation of maternal health programs in the Ethiopian communities. It will be used to increase the awareness of women on cervical screening behavior and as base line information for researchers, health professionals, NGOs and as a whole the society to understand about the cervical cancer screening practice.

Early screening for cervical cancer is a key intervention in reduction of maternal deaths. . Health care workers have a significant contribution to improve cervical cancer screening practice among women and inexpensive, "screen and treat" approach to cervical cancer prevention. Increasing awareness on cervical cancer screening practice an effective strategy to prevent and cure for women in low-resource countries. Cervical cancer screening practice various factors including cultural, and beliefs about the disease and the health care system were found to affect the treatment seeking behavior for CC. One of the barriers included: stigma associated with disease, limited access to health services, the lack of awareness, and the asymptomatic nature of the disease. Therefore, the purpose of this study is to assess Cervical cancer screening practice and associated factors among women attending gynecology out -patient department at Mettu Karl referral Hospital, South west, Ethiopia, 2019.

\section{Conceptual Framework}

[See figure 1]

\section{General objective}

To assess factors affecting Cervical cancer screening practice among women attending gynecology out -patient department at Mettu Karl referral Hospital, South west, Ethiopia, 2019.

\section{Specific objectives}

To asses awareness on the cervical cancer screening practice among women attending GYN OPD at, Mettu Karl referral Hospital, South west, Ethiopia, 2019

To identify factors associated to cervical cancer screening practice among women attending GYN OPD at Mettu Karl referral Hospital, South, west, Ethiopia, 2019

\section{Method And Material}

\section{Study area and period}

The study area was governmental hospitals in llubabor zone. One of oromia region which is located $600 \mathrm{~km}$ away from the capital city, Addis Ababa, Ethiopia. It is bordered on the south by the south nation, nationality and Peoples , on the southwest by the Gambela , on the west by kelem welega zone, on the north by mirab wellega zone, and Benishanigul -gumuz Region, on the northwest by misirak welega zone, and on the east by Jima zone. with an area of $15,135.33$ square kilometers. 
There are two public hospitals (mettu karl referral hospital and darimu hospital) which are delivering maternal and child health service.

\section{Study design}

Institutional based cross sectional study design was used to assess cervical cancer screening practice and associated factors among women attending Gynecology, out -patient department at mettu karl referral hospital.

\section{Sources of Population.}

All women's who came to Mettu Karl referral hospital outpatient department for all service during data collection period.

\section{Study populations}

All women who visited to Gynecology outpatient departments at Mettu Karl referral Hospital during data collection period.

\section{Inclusion and exclusion criteria}

\section{Inclusion Criteria}

All women attending gynecological out patients at the time of data collection

\section{Exclusion Criteria}

Women who are acutely sick at the time of data collation and age less than 21

\section{Sample size determination}

Sample size calculation is based on single population proportion formula as follow

$$
\begin{gathered}
n=. \underline{(z a / 2)} \cdot \underline{2} . p(1-p)- \\
d^{2} \\
n_{0} \equiv(\underline{1.96}) \cdot \underline{2} \underline{0.572}(\underline{1-0.572}) \\
(0.05)^{2} \\
n=376
\end{gathered}
$$

- Since the total population is less than 10,000 , correction formula is used as follows:

$$
\begin{array}{r}
\mathrm{n}=\underline{\mathrm{no}} \\
1+\underline{\mathrm{no}} \\
\mathrm{N} \\
\mathrm{n}=376
\end{array}
$$




$$
1+\underline{376}
$$

1306

$$
n=292
$$

Then, by considering $10 \%$ non-response rate:

$\mathrm{n}=292 \times 10 \%+292$

$\mathrm{n}=321$

Where:

- $\mathrm{n}=$ Sample size required for the study

- $\mathrm{Za} / 2=1.96$, standardized normal distribution curve value for the $95 \%$ confidence interval

- $p=0.572$ from previous study

- $d=0.05$ degree of margin of error

- $\mathrm{N}=$ Total population for the study

\section{Sampling and sampling procedure}

Mettu Karl referral hospital is selected for this study, Gynecology outpatient department and MCH is selected purposively from the hospital. Total sample size is allocated to each compartment proportionally. Finally the actual study participants are selected by systematic random sampling technique which is $K=N / n=2006 / 321=6$, then 2 is randomly selected. Then individual patients was selected every six by considering their order of visit as sampling frame.

Proportional allocation,

$$
\mathrm{n}_{\mathrm{j}}=\underline{\mathrm{n} \times \mathrm{N}_{\mathrm{j}}}
$$

N

Where: $\mathrm{nj}=$ is the sample size of the jth unit

$\mathrm{Nj}=$ is population size of the $\mathrm{jth}$ unit

$n=n 1+n 2+n 3+n 4 \ldots$ is the total sample size (321)

$\mathrm{N}=\mathrm{N} 1+\mathrm{N} 2+\mathrm{N} 3+\mathrm{N} 4+\mathrm{N} 5 \ldots$ is total population size (2006)

\section{Variables}

Dependent variables

Cervical cancer screening practice

Independent variables

- Socio demographic factors 
- Age

- Sex

- Income

- Marital Status

- Ethnicity

- Religion

- Educational status

- Personal factor

- Multiple sexual partners

- Early initiation of sex

- Multiparity

- Contraceptive use

- Fear of screening

- Smoking status

- Organizational factor

- Availability

- Accessibility

- Resource

\section{Operational Definitions}

For the purpose of this study, the following definitions will be applied and used within the context in which they are explained:

Cervical cancer- means a disease in which cancer cells grow in the cervix. .

Cervical cancer screening practice- means procedure used to detect abnormal cells of the cervix. In this study, screening procedures refer to VIA or a Pap smear

Multiple sexual partners: Having lifetime partners greater than two.

Multiparty: Having parity greater than two

Early initiation of sex: Starting first sexual intercourse before the age of 18 years

Contraceptive use: Defined as use either of the contraceptives: oral contraceptives (pills), inject able, implants, IUCD for more than or equals one month period.

Organizational barriers; Organizational barriers were factors which affected the accessibility of healthcare services to the women.

\section{Data Collection technique}

An interviewer administered semi structured questionnaire was adapted by reviewing similar studies (50). Data was collected by 6 trained nurses. Data was collected from the clients after getting verbal consent through informed consent in the health facility. Data was collected using structured interviewer administered questionnaire was 
prepared in English after reviewing literatures of similar surveys that have been carried out previously then final modified English questionnaire was translated to Amharic. The interview was taken 20 to 30 minute.

\section{Data Quality Assurance}

The questionnaires were pre-tested on $5 \%$ of the sample size at darimu district Hospital to avoid any confusion during actual data collection period. The data collectors were trained before actual

data collection and the principal investigator was supervising the data collector closely. During data collection, both principal investigator and data collectors were check the data for its

completeness and missing information at each point. Furthermore the data was coded, checked and cleared during entry.

\section{Data Analysis}

After the collection of data, the questionnaire was checked for completeness and consistency. Then, the data template format was prepared, coded and entered in to Epi Data version 4.2. Then data was exported to SPSS version 21 for analysis. Descriptive analysis was employed to describe the percentages and distributions of the respondents for socio-demographic characteristics. Bivariate and multivariate analysis was used for association of independent variable with dependent variable. Crude and adjusted odds ratios with the corresponding 95\% confidence intervals were computed. P-value $<0.05$ was considered statistically significant in this study. Then, the results were presented in the form of tables, graphs and charts

\section{Ethical consideration.}

Paper of approval and letter for permission was obtained before the beginning of data collection from review board of School of Nursing and Midwifery, College of Health Sciences, Mettu University. Permission letter was provided for Mettu Karl referral hospital. After that participants were explained clearly about the purpose and procedure of data collection, and then confidentiality and privacy were guaranteed. It is also cleared that participation were fully based on the willingness of participants using verbal consent.

\section{Dissemination plan}

The result of this study will be disseminated to Mettu University College of health science library and universities included in the study. Possible publication on international reputable peer reviewed journals will be sought and concerned bodies.

\section{Results}

\section{Socio-Demographic Characteristics}

This study assessed cervical cancer screening practices and associated factors. The total of 320 clients was participated in the study giving a response rate of $99 \%$ and most of the respondents(34.9\%) were in the age range between 30-39 years, with the mean age of 35.79 with SD 11.46 . Regarding to religion, the majority of the participants 169(52.6\%) were orthodox Christian and the least covers for catholic 33(10.3\%). All the socio demographic characters are presented in the table below (table1).

Table1: Socio-demographic characteristics among women attending gynecology OPD and MCH at MK referral hospital, 2019 


\begin{tabular}{|c|c|c|c|}
\hline Socio demographic variables & & Frequency(n) & Percent (\%) \\
\hline \multirow[t]{4}{*}{ Age } & $21-29$ & 109 & 34.0 \\
\hline & $30-39$ & 112 & 34.9 \\
\hline & $40-49$ & 68 & 21.2 \\
\hline & $\geq 50$ & 32 & 10.0 \\
\hline \multirow[t]{8}{*}{ Level of education } & Don't write and read & 67 & 20.9 \\
\hline & Only read and write & 36 & 11.2 \\
\hline & primary(1-4) & 48 & 15.0 \\
\hline & primary(5-8) & 46 & 14.3 \\
\hline & secondary $(9-10)$ & 44 & 13.7 \\
\hline & Preparatory & 26 & 8.1 \\
\hline & Diploma & 32 & 10.0 \\
\hline & Higher & 22 & 6.9 \\
\hline \multirow[t]{6}{*}{ Marital status } & Single & 43 & 13.4 \\
\hline & Married & 165 & 51.4 \\
\hline & Widowed & 41 & 12.8 \\
\hline & Divorced & 41 & 12.8 \\
\hline & Separated & 31 & 9.7 \\
\hline & $\leq 15$ & 18 & 5.6 \\
\hline \multirow[t]{2}{*}{ How old when you first marriage? } & $15-17$ & 49 & 15.3 \\
\hline & $\geq 18$ & 211 & 65.7 \\
\hline \multicolumn{4}{|l|}{ Income } \\
\hline & $451-900$ & 116 & 36.1 \\
\hline & $\geq 901$ & 200 & 62.3 \\
\hline \multirow[t]{6}{*}{ Occupation } & House & 89 & 27.7 \\
\hline & Merchant & 57 & 17.8 \\
\hline & daily laborer & 52 & 16.2 \\
\hline & Governmental & 44 & 13.7 \\
\hline & Private & 48 & 15.0 \\
\hline & Others & 31 & 9.7 \\
\hline \multirow[t]{4}{*}{ Religion } & Orthodox & 169 & 52.6 \\
\hline & Muslim & 56 & 17.4 \\
\hline & Protestant & 63 & 19.6 \\
\hline & Catholic & 33 & 10.3 \\
\hline
\end{tabular}

Reproductive health characteristic

Among the study participant, 253(78.8\%) currently use contraceptives, among the reported, the majority of the participants $117(36.4) \%$ were used implant as shown in the figure below.

Among the study subjects, $147(45.8 \%)$ had regular menstrual history, and the least 28(8.7\%) were no menses. The majority of respondents $184(57.3 \%)$ of their age at menarche were $\leq 12,24(7.5 . \%) 15$ and above years, respectively. Regarding coital bleeding the majority of participants $228(71.0 \%)$ had bleeding. Among the study subjects, $133(41.4 \%)$ had parity $2-4$, were $58(18.1 \%)$ of the study participants had parity $>$ 5.Age of the respondents when they gave birth to their first child, 160(49.8\%) was less than 20 years old, in the mean and standard deviation of age at first birth 1.59 \pm 0.814 years respectively. In addition, 199(62.0\%) had average birth interval less than two years, were 52(16.2\%) had average birth interval 2-3years.Among the participants $6(1.9 \%)$ had history of abortion and $127(39.6 \%)$ had family history of cervical cancer (see table 2 ). 


\begin{tabular}{|c|c|c|c|}
\hline Variables & & Frequency(n) & Percentage (\%) \\
\hline How old were you menarche & $\begin{array}{l}\leq 12 \\
13-14 \\
\geq 15\end{array}$ & $\begin{array}{l}184 \\
113 \\
24\end{array}$ & $\begin{array}{l}57.3 \\
35.2 \\
7.5\end{array}$ \\
\hline Menstrual history & $\begin{array}{l}\text { Regular } \\
\text { sometimes } \\
\text { Always irregular } \\
\text { No menses }\end{array}$ & $\begin{array}{l}147 \\
98 \\
48 \\
28\end{array}$ & $\begin{array}{l}45.8 \\
30.5 \\
15.0 \\
8.7\end{array}$ \\
\hline Coital bleeding & $\begin{array}{l}\text { No } \\
\text { Yes }\end{array}$ & $\begin{array}{l}228 \\
93\end{array}$ & $\begin{array}{l}71.0 \\
29.0\end{array}$ \\
\hline Have you ever give birth & Yes & $\begin{array}{l}49 \\
272\end{array}$ & $\begin{array}{l}15.3 \\
84.7\end{array}$ \\
\hline How old when you give first birth & $\begin{array}{l}<20 \\
20-25 \\
26-30\end{array}$ & $\begin{array}{l}160 \\
71 \\
33\end{array}$ & $\begin{array}{l}49.8 \\
22.1 \\
10.3\end{array}$ \\
\hline Average birth interval & $\begin{array}{l}>31 \\
<2 \\
2-3 \\
.>3\end{array}$ & $\begin{array}{l}8 \\
199 \\
52 \\
22\end{array}$ & $\begin{array}{l}2.5 \\
62.0 \\
16.2 \\
6.9\end{array}$ \\
\hline Experience abortion & $\begin{array}{l}\text { No } \\
\text { Yes }\end{array}$ & $\begin{array}{l}218 \\
103\end{array}$ & $\begin{array}{l}67.9 \\
32.1\end{array}$ \\
\hline How many times do You have abortion & $\begin{array}{l}1 \\
2-4 \\
>5 \\
\text { No } \\
\text { Yes }\end{array}$ & $\begin{array}{l}82 \\
133 \\
58 \\
194 \\
127\end{array}$ & $\begin{array}{l}25.5 \\
41.4 \\
18.1 \\
60.4 \\
39.6\end{array}$ \\
\hline
\end{tabular}

Table 2: related to reproductive health characteristics among women attending gynecology OPD and MCH at MK referral hospital, 2019

Intention to use cervical cancer screening practice and barriers characteristics of women screened for cervical cancer

The majority of participants 225(70.1\%) were not intended cervical cancer screening practice while 96 (29.9\%) were intended cervical screening respectively.

Among women who had cervical screening test, 49(15.3\%) were positive and 46(14.3\%) were negative. Regarding the main reason for not intending to have cervical screening was lack of health education programs in this area $70(21.8 \%)$ while $37(11.5 \%)$ were due to the cost of price. Among participants, $147(45.8 \%)$ had cervical cancer screening practiceplan as shown in the table below.

Table 3: Intention to use cervical cancer screening practiceand barriers characteristics among women attending gynecology OPD and MCH at MK referral hospital, 2019

\begin{tabular}{llll}
\hline Variables & & Frequency(n) & Percentage(\%) \\
\hline Screening test & Positive & 49 & 15.3 \\
Barrier of cervical cancer screening & negative & 46 & 14.3 \\
& 1 & 38 & 11.8 \\
& 2 & 37 & 11.5 \\
\multirow{2}{*}{ Do you have a plan for cervical screening } & 3 & 70 & 21.8 \\
& 4 & 43 & 13.4 \\
& Yes & 147 & 45.8 \\
& No & 63 & 19.6
\end{tabular}


Lifestyle and sexual behavior factors barriers characteristics of women screened for cervical cancer

Among the study participants 53(16.5\%) had history of smoking. Concerning age for first sex, at the age of 17years old and above 249 (77.6\%) of the respondents had started sex and 72(22.4\%) were age at first sex less than 16 years old. Among the study participants, $178(55.5 \%)$ had history of pelvic infection, 53(16.5\%) had history of STI, and 51(15.9\%) had history of STI in their husband (see Table $4)$.

Table 4: lifestyle and sexual behavior factors barriers characteristics of women screened for cervical cancer in MK, Southern, Ethiopia, 2019

\begin{tabular}{llll}
\hline Variables & & Frequency(n) & Percentage(\%) \\
\hline Have you ever smoke & No & 268 & 83.5 \\
& yes & 53 & 16.5 \\
How old were you when you first had sex & $<16$ & 72 & 22.4 \\
& $>17$ & 249 & 77.6 \\
Pelvic infection & No & & \\
& yes & 143 & 44.5 \\
Do you have STI & No & 178 & 55.5 \\
& yes & 268 & 83.5 \\
Partner STI & & 53 & 16.5 \\
Sexual partner & No & 270 & 84.1 \\
& yes & 51 & 15.9 \\
If yes haw many & 1 & 178 & 55.5 \\
& 2 & 176 & 42.4 \\
& $\geq 3$ & 136 & 2.2 \\
& & 7 & 66.0 \\
& 0 & 212 & 15.3 \\
\hline
\end{tabular}

Factors of cervical cancer screening practice

Bivariate analysis revealed that sixteen out of thirty two variables showed a significant

association with cervical cancer screening practice at a $5 \%$ level of significance. For further analysis, all independent variable which fulfilled the minimum requirement for multivariable logistic regression (had significant association at a $\mathrm{p}<0.25$ ) were entered. The highest risk factors for not good cervical cancer screening practice was found in those individuals with educational level Don't write and read 67 (20.9\%), $\geq 901$ average monthly income 200(62.3\%), age $\geq 18$ at first marriage 211(65.7\%), <2 average birth interval 99(62.0\%). However, bad cervical cancer screening practice was not statistically different among the above variables $(P>0.05)$.

The study participants those who have age greater than or equal to 50 were fourteen times more likely have bad cervical screening behavior(COR=13.830,95\% CI 5.466,34.990) than those who have age 21-29 years. The participants who were use contraceptive had odds of 0.206 times cervical cancer screening practice $(\mathrm{COR}=0.206,95 \% \mathrm{CI}=0.094,0.447)$ than those who did not use contraceptive.

The participants who were smoking of had 23.9 times cervical cancer screening practice with $(\mathrm{COR}=0.239 ; 95 \% \mathrm{CI}=0.130,0.438)$ than not practicing smoking, Women who had history of sexual transmitted diseases of had odds 0.109 times cervical cancer screening practice with $(\mathrm{COR}=0.109 ; 95 \% \mathrm{CI}=0.56,0.212) \quad$ compared to those who did not have history of sexually transmitted diseases and Having two or more life time sexual partners of the husband had odds 0.754 times bad cervical cancer screening practice behavior with(COR $=0.754 ; 95 \% \mathrm{CI}=0.352,1.6160)$ compared to those individuals who had one sexual partner.

Those participants who had age $\geq 50$ were about twenty six times more likely with $(\mathrm{AOR}=26.603$ 
;95\%CI=8.167,86.662), age between 40-49 (AOR=4.152,95\%CI=1.630,10.576) were four times more likely and age between 30-39 three times more likely had bad cervical screening behavior compared to those age between 21-29. In this study individuals who had smoking practices were a factor of 0.179 times less likely with $(\mathrm{AOR}=0.179 ; 95 \mathrm{CI}=0.087,0.369)$ had bad cervical cancer screening practice than those who had no smoking practices. Participants who were used contraceptive with a factor of 0.172 times less likely had cervical cancer screening practice with(AOR $=0.172 ; 95 \% \mathrm{CI}=0.070,0.422$ ) compared to those who were not used any contraceptive. In addition, women's who had STD were more likely had association with cervical cancer screening practice with $(\mathrm{AOR}=0.169 ; 95 \% \mathrm{CI}=0.82$, 0.347) than who had no STD and respondents who had two or more life time sexual partners of the husband had a factor of one times more likely at risk for cervical cancer screening practice with $(\mathrm{AOR}=2.973 ; 95 \% \mathrm{CI}=1.414-6.247)$ compared to those respondents who had one sexual partner of the husband.

Table5. Results of bivariate and multivariate analysis for Cervical cancer screening practice and associated factors among women attending gynecology out -patient department at MK referral Hospital, South west, Ethiopia, 2019. 


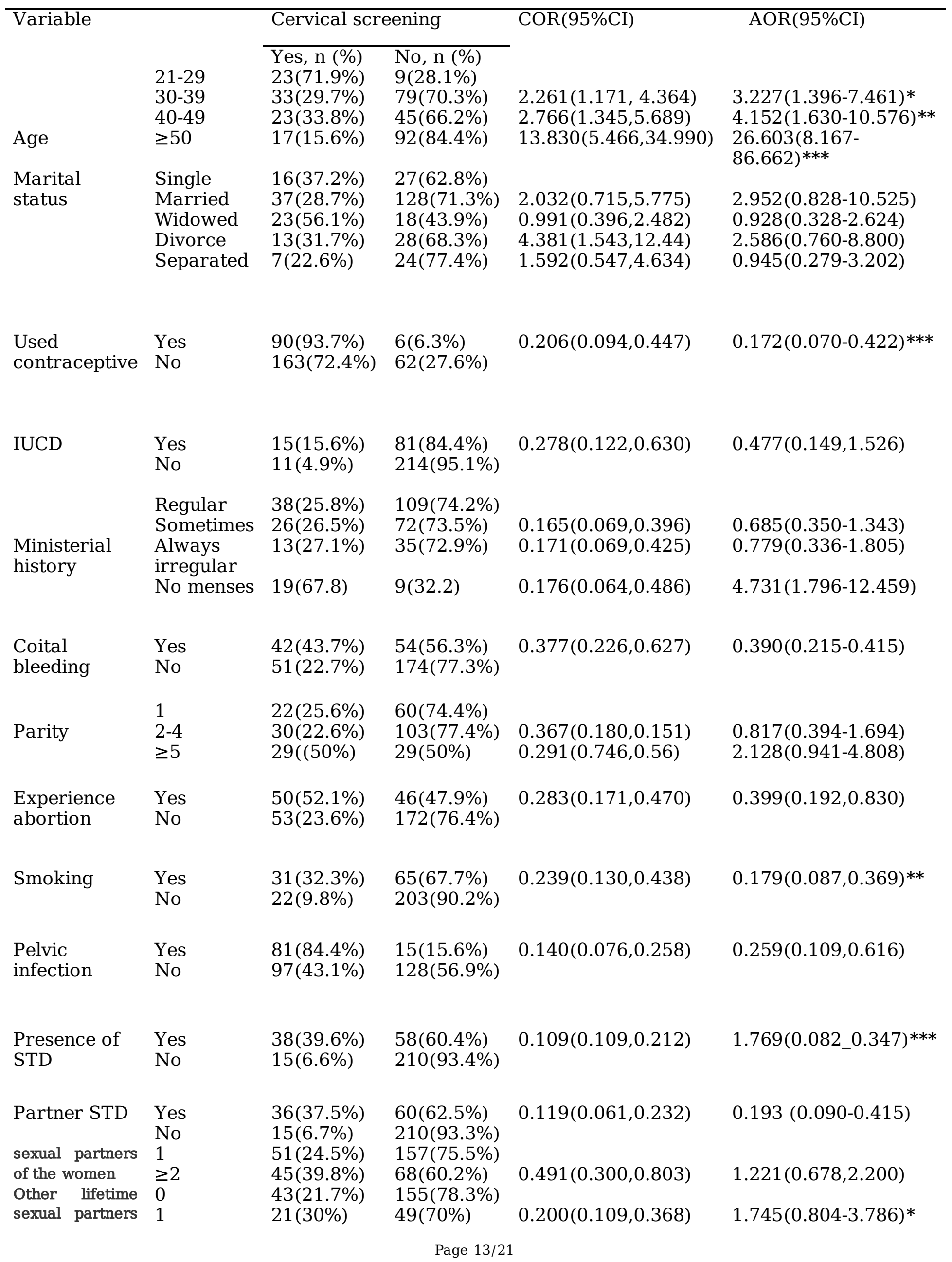




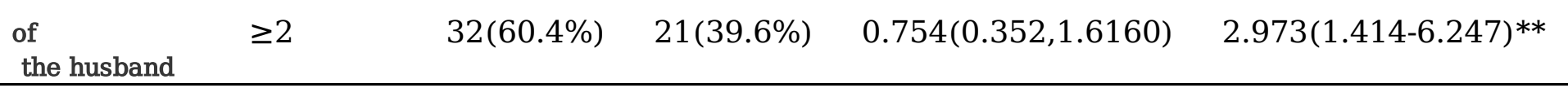

$\mathrm{P}<0.05 *, \mathrm{P}<0.01 * *, \mathrm{P}<0.001 * * *$

\section{Discussion}

The broad purpose of this research was to better understand cervical cancer screening practice and associated factors among women attending Gynecology, out -patient department at MK referral hospital. Among the total of study participant 320 , the current study found that the participation rate in screening for cervical cancer is about $29.9 \%$. However, this finding is higher than $9.6 \%$ in Gamo Gofa (26) , $18.8 \%$ in studies carried out in Nepal(27),19.8\% in Mekele (28) and less than another study conducted in Uganda $48 \%(51,23,51,53)(29)$. This may partly be due to difference in socio-demographic characteristic of the subjects of the studies and sample size difference. According to the current study, the main reason of not taking cervical cancer screening practice service is lack of health education.

Factors associated with cervical cancer screening practice were also assessed. This study reveals that women's age, contraceptive usage, intending smoking, presence of STD and multiple sexual partner of the husband were found to be associated factor for cervical cancer screening practice. In this study age group of $\geq 50$ years 26.603 times had association with cervical cancer screening practice with $(\mathrm{AOR}=26.603 ; 95 \% \mathrm{Cl}=8.167,86.662)$ compared to age between 21-29, while age 30-39 years 3.227 times had significant association cervical cancer screening practice $(A O R=3.227,95 \% \mathrm{Cl}=1.396,7.461)$ compared to age between 21-29. There are also researches with the same findings in Mekele (26), which showed that all other age groups of women years were have association with cervical screening behavior compared with age $\geq 50$. Additionally, study conducted in northwest Ethiopia showed that, woman in the age range of $30-39$ were 1.78 times $(\mathrm{AOR}=2.78,95 \% \mathrm{Cl}$

$=1.71-7.29)$ higher than women age $21-29$ had significantly associated with cervical cancer screening practice (30, 31)

This study also revealed that women's who had intended smoking were found to be $17.9 \%$ times associated factors for bad cervical cancer screening practice with $(A O R=0.179 ; 95 \mathrm{Cl}=0.087,0.369)$. Similar studies conducted in Kenya and this study showed that those participants who were used contraceptive had significant association cervical cancer screening practice with $(\mathrm{AOR}=0.172 ; 95 \% \mathrm{Cl}=0.070,0.422)$ than those who had no contraceptive usage. This is comparable with similar study conducted in Kenya showed that those individuals who were used contraceptive had significant association with cervical screening behavior (31)

Another finding of the current study is having history of multiple sexual partner of the husband also found to have 2.973 times association for cervical cancer screening practice with (AOR=2.973; 95\% Cl=1.414-6.247) compared to having one sexual partner of the husband while having one sexual partner of the husband also found to have one times association for cervical cancer screening practice behavior than not having multiple sexual partner of the husband. The same result reported from mekelle showed that women who have history of multiple sexual partners were 1.635 times association for cervical cancer screening practice with $(\mathrm{AOR}=1.635,95 \% \mathrm{Cl}=1.094-2.443)$ Also study conducted in Yirgalem showed that having multiple sexual partner of the husband had significant association with cervical cancer screening practice with (AOR=40; 95\% Cl: 22.44,70.204)(32,33)

In this study having history of sexual transmitted disease was times 0.169 more likely had association with cervical cancer screening practice with $(\mathrm{AOR}=0.169 ; 95 \% \mathrm{Cl}=0.82,0.347)$. In addition, similar findings of study conducted in Finote Selam Town North west Ethiopia showed that having history of STDs were nearly 2.75 times had association with cervical cancer screening practice with(AOR=2.75, 95\%Cl: $1.24,6.04)(34)$ same result was also reported from 
Mekele, where women with history of sexually transmitted disease were 4.129 times had significant association with the cervical screening behavior with $(\mathrm{AOR}=4.129,95 \% \mathrm{Cl}=2.281-7.476)(32)$

\section{Limitations}

- As the respondents had to remember when they had performed cervical cancer screening, there might have been recall bias.

- Being a cross sectional study; it cannot show cause-effect relationship between the variables studied.

\section{Conclusion And Recommendations}

According to this finding, the overall rate of those participants who had awareness on cervical cancer screening practice were about $29.9 \%$. Maternal age, using smoking, using contraceptives, presence of sexually transited disease, and having multiple sexual partner of the husband are predominantly stated factors associated with cervical screening.

- Ilubabor Zone health birau

- Focus preventive health measures for cervical cancer screening practice and its prevention.

- Should provide awareness campaigns targeting illiterate groups can be conducted in community so that they become motivated towards cervical cancer screening

- Should provide educational interventions to improve uptake of cervical screening with time and to increase selfefficacy and perceived focus of control about cervical cancer.

- Should done on awareness creation and sensitization of health workers on cervical cancer screening practice and sustaining national screening programs widely.

- MK Hospital health professionals who are assigned to cervical cancer screening clinics and community health workers

- Health workers need to be marked at first since they have role in any potential screening activities in order to achieve screening coverage in the community.

- Conduct health education programs to the women eligible for screening attending gynecological clinic regarding prevention of cervical cancer and importance of cervical cancer screening.

- Should provide women with choice from whom they want to be screened

- Ministry of Health together with other stakeholders

- To embark on intensive awareness creation campaigns on cervical cancer to complement health education in health facilities.

- Ethiopian Cancer Association and other health groups should reading materials as well as different campaign for awareness creation.

\section{Abbreviations}


AAPBCR, Addis Ababa population based cancer registry CC , Cervical Cancer CCS, Cervical Cancer Screening

$\mathrm{Cl}$,Confidence Interval FIGO,International Federation of Gynecology and Obstetrics

GP , General Practitioner HPV , Human Papilloma Virus $\mathrm{MOH}$, Ministry Of Health

MKRH, Mettu Karl referral hospital ETB, Ethiopian Birr VIA, Visual Inspection with Acetic Acid

Pap, Papanicolaou test, SPSS, Statistical Packages for Social Sciences WHO, World Health Organization

\section{Declarations}

\section{ACKNOWLEDGEMENTS}

First I would like to express my gratitude to mettu University ,college of health science (SAHS), and Department of nursing

\section{Authors' contributions}

Conceived and designed by DN performed data analysis and interpreting of findings and Prepares manuscript and approved the final manuscript.

\section{Funding}

No funding was obtained for this study

\section{Competing interests}

The Author declare that they have no competing interests

\section{Ethical considerations}

Ethical clearance was obtained from the Institutional Review Board of Mettu University. An official permission letter was secured from the Illu Aba Bor Zone health office. All mothers were informed about the purpose of the study, and interview was held only with those who agreed to give verbal consent to participate. The right of a participant to withdraw from the study at any time, without any precondition was disclosed unequivocally. Moreover, the confidentiality of information was guaranteed by all data collectors and investigators by using code numbers rather than personal identifiers and by keeping the questionnaire locked.

\section{Authors' details}

${ }^{1}$ Dessalegn Nigatu (DN) (BSc, MSc) Department of Nursing, College of health Science, Mettu University, Mettu, Ethiopia.

\section{Corresponding Author:}

Dessalegn Nigatu Rundasa (DN), Email: dessuko2013@gmail.com tell phone: +251912002398

Affiliation: Bsc in Nursing, Msc in pediatrics and child health, Department of Nursing, College of Health science, Mettu University, Ethiopia

\section{References}


1. Society AC. ACS cancer detection guidelines. Retrieved from

http://www.cancer.org/docroot/ped/content/ped_2_3x_acs_cancer_detection_guidelines_36.asp. journal . (2014).

2. Smith RA, von Eschenbach AC, Wender R, Levin B, Byers T, Rothenberger D, et al. American Cancer Society guidelines for the early detection of cancer: update of early detection guidelines for prostate, colorectal, and endometrial cancers: Also: update 2001-testing for early lung cancer detection. CA: a cancer journal for clinicians. 2001;51(1):38-75.

3. Ferlay J SI, Dikshit R, Eser S, Mathers C, Rebelo M, Parkin DM, Forman D, Bray F. Cancer incidence and mortality worldwide: sources, methods and major patterns . ; 136: E359-E386 [PMID: 25220842 DOI: 10.1002/ijc.29210] International journal , 2015. 2015.

4. Bray F, Ferlay J, Soerjomataram I, Siegel RL, Torre LA, Jemal A. Global cancer statistics 2018: GLOBOCAN estimates of incidence and mortality worldwide for 36 cancers in 185 countries. CA: a cancer journal for clinicians. 2018;68(6):394-424.

5. Harcourt N, Ghebre RG, Whembolua G-L, Zhang Y, Osman SW, Okuyemi KS. Factors associated with breast and cervical cancer screening behavior among African immigrant women in Minnesota. Journal of immigrant and minority health. 2014;16(3):450-6.

6. Guvenc G, Akyuz A, Açikel $\mathrm{CH}$. Health belief model scale for cervical cancer and Pap smear test: psychometric testing. Journal of advanced nursing. 2011;67(2):428-37.

7. Debbie S. DS, Herschel W., Maureen K.,Shalini L.,Joanna C., et al.. . American Cancer Society, American Society for Colposcopy and Cervical Pathology, and American Society for Clinical Pathology Screening Guidelines for the Prevention and Early Detection of Cervical Cancer. journal for clinician 2012;8:62:147-72.

8. Solomon D, Breen N, McNeel T. Cervical cancer screening rates in the United States and the potential impact of implementation of screening guidelines. CA: A Cancer Journal for Clinicians. 2007;57(2):105-11.

9. Adewole IF, Abauleth YR, Adoubi I, Amorissani F, Anorlu RI, Awolude OA, et al. Consensus recommendations for the prevention of cervical cancer in sub-Saharan Africa. Southern African Journal of Gynaecological Oncology. 2013;5(2):47-57.

10. report G. Human papillomavirus (HPV) and related cancers in the Global Alliance for vaccines and immunization. November 2012.

11. Carmen W. H. Chan 1, Kai Chow Choi 1, RSW. Examining the Cervical Screening Behaviour of Women Aged 50 or above and Its Predicting Factors: A Population-Based Survey. Journal. 2016.

12. Birhanu Z, Abdissa A, Belachew T, Deribew A, Segni H, Tsu V, et al. Health seeking behavior for cervical cancer in Ethiopia: a qualitative study. International journal for Equity in health. 2012;11(1):83.

13. Catherine McCarey DP, Pierre Marie Tebeu, Michel Boulvain, Anderson Sama, Petignat DaP. Awareness of HPV and cervical cancer prevention among Cameroonian healthcare workers,.. BMC,. 2011. 
14. Gebremariam T. Human papillomavirus related cervical cancer and anticipated vaccination challenges in Ethiopia. International journal of health sciences. 2016;10(1):137.

15. Bruni L, Barrionuevo-Rosas L, Albero G, Aldea M, Serrano B, Valencia S. Human papillomavirus and related diseases. The World: Ico Information Centre On Hpv And Cancer (Hpv Information Centre). 2016.

16. Chang C-C. Understanding the screening behavior in mothers and adolescent daughter's human papillomavirus vaccine uptake-the transtheoretical model. IJHSR. 2014;4:228-34.

17. WHO. Comprehensive cervical cancer control: a guide to essential practice (2nd edn.), Geneva. Journal. 2014.

18. Ferlay J, Shin HR, Bray F, Forman D, Mathers C, Parkin DM. Estimates of worldwide burden of cancer in 2008: GLOBOCAN 2008. International journal of cancer. 2010;127(12):2893-917.

19. t. s. knowledge, attitude, practice of cervical cancer screening and its associated factors among female students in hawassa universitycollege of medicine and health science hawassa. journal. 2015.

20. Li-Wei Wu L-PL, Si-Fan Chen, Shang-Wei Hsu, Ching-HuiLoh, Chia-Ling Wu, Jin-Ding Lin. Knowledge and attitudes regarding cervical cancer screening among women with physical disabilities living in the community. BMC Health Services Research. 2011;2.

21. ebabekela. assessment of knowledge and attitude of cervical cancer and screening among primary health care workers of west wollega zone, ethiopia,2016.

22. MAREE J.E. LMWSCD. combining breast \& cervical screening in attempt to increase cervical cancer screening up take. An intervention study in a South Africancontext, . European Journal of Cancer care. 2011;30(211).

23. Gebrie MH BM, Lemlem SB, Woreta HK-, 6156.1000569. Knowledge, Preventive Practice and

Associated Factors of Female Nurses' Towards Cervical Cancer in the Selected Government Hospitals in Addis Ababa, Ethiopia. . Journal. 2015;6(569).

24. Abate S. Trends of cervical cancer in Ethiopia. Cervical Cancer. 2015;1(1):1-4.

25. Ali F KR, Wassie. Understanding cervical cancer in the context of developing countries. Ann Trop Med Public Health. $2012 ; ; 5$.

26. Gebru Z, Gerbaba M, Dirar A. Utilization of cervical carcinoma screening service and associated factors among currently married women in Arba Minch Town, Gamo Gofa Zone, Southern Ethiopia 2014.

27. Thapa N, Maharjan M, Petrini MA, Shah R, Shah S, Maharjan N, et al. Knowledge, attitude, practice and barriers of cervical cancer screening among women living in mid-western rural, Nepal. Journal of gynecologic oncology. 2018;29(4).

28. Gebreegziabher M, Asefa NG, Berhe S. Factors affecting the practices of cervical cancer screening among female nurses at public health institutions in Mekelle town, Northern Ethiopia, 2014: a cross-sectional study. Journal of Cancer Research. 2016;2016.

29. Nakisige C, Schwartz M, Ndira AO. Cervical cancer screening and treatment in Uganda. Gynecologic oncology reports. 2017;20:37-40. 
30. Chan CW, Choi KC, Wong RS, Chow KM, So WK, Leung DY, et al. Examining the cervical screening behaviour of women aged 50 or above and its predicting factors: a population-based survey. International journal of environmental research and public health. 2016;13(12):1195.

31. Boka A, Nigatu D. Cervical cancer screening and associated factors among women attending gynecology outpatient department and maternal and child health atmettu karlreferralhospital, South West, Ethiopia, 2019. International Journal of Current Research in Life Sciences. 2019;8(01):2934-44.

32. Teame H, Gebremariam L, Kahsay T, Berhe K, Gebreheat G, Gebremariam G. Factors affecting utilization of cervical cancer screening services among women attending public hospitals in Tigray region, Ethiopia, 2018; case control study. PloS one. 2019;14(3):e0213546.

33. Abamecha F, Tena A, Kiros G. Psychographic predictors of intention to use cervical cancer screening services among women attending maternal and child health services in Southern Ethiopia: the theory of planned behavior (TPB) perspective. BMC public health. 2019;19(1):1-9.

34. Geremew AB, Gelagay AA, Azale T. Uptake of pre cervical cancer screening service and associated factors among women aged 30-49 years in Finote Selam town Northwest Ethiopia. International Journal of Collaborative Research on Internal Medicine \& Public Health. 2018;10(2):0-.

\section{Figures}

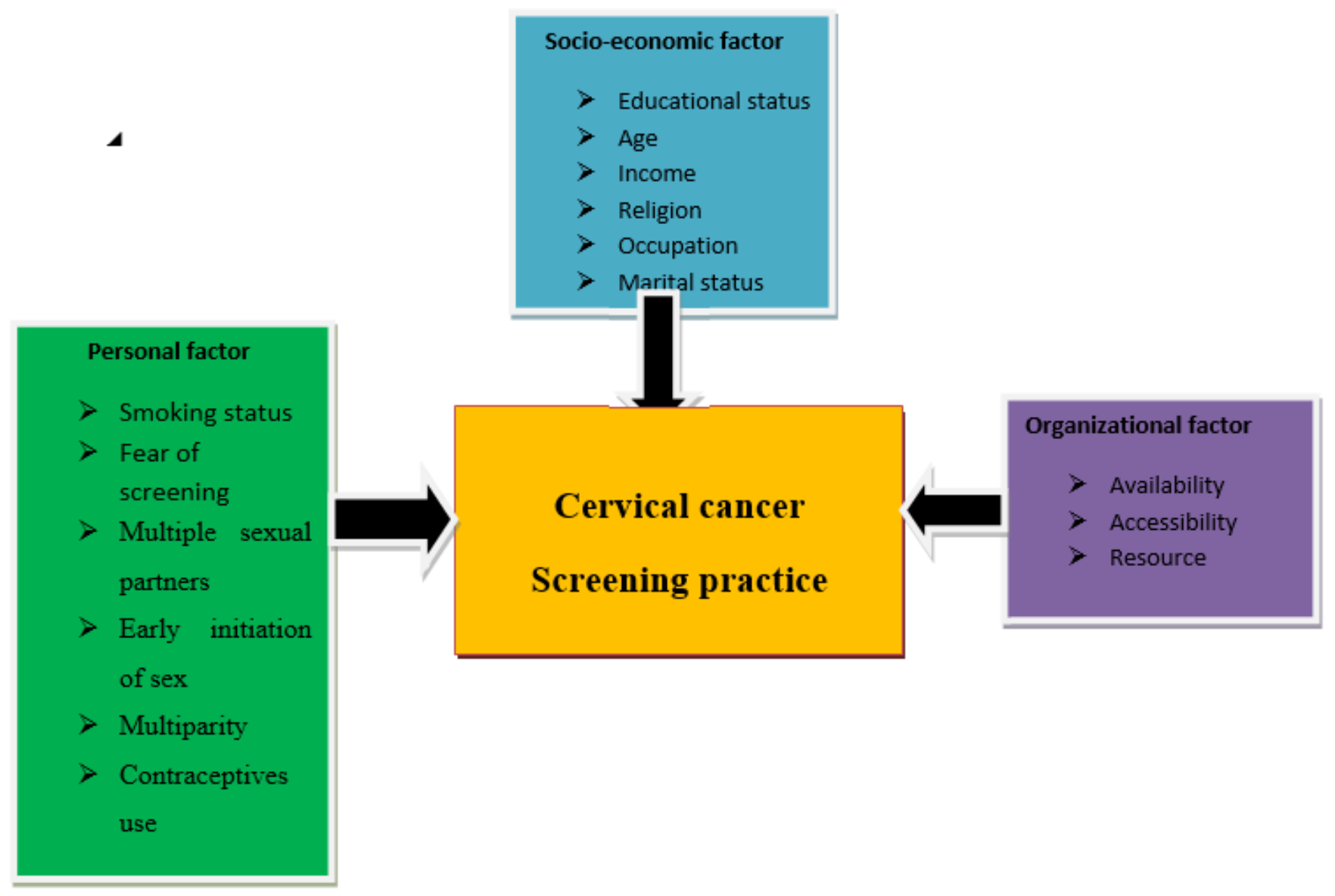

Figure 1 
Cervical cancer screening practice conceptual frame work modified from different literature.

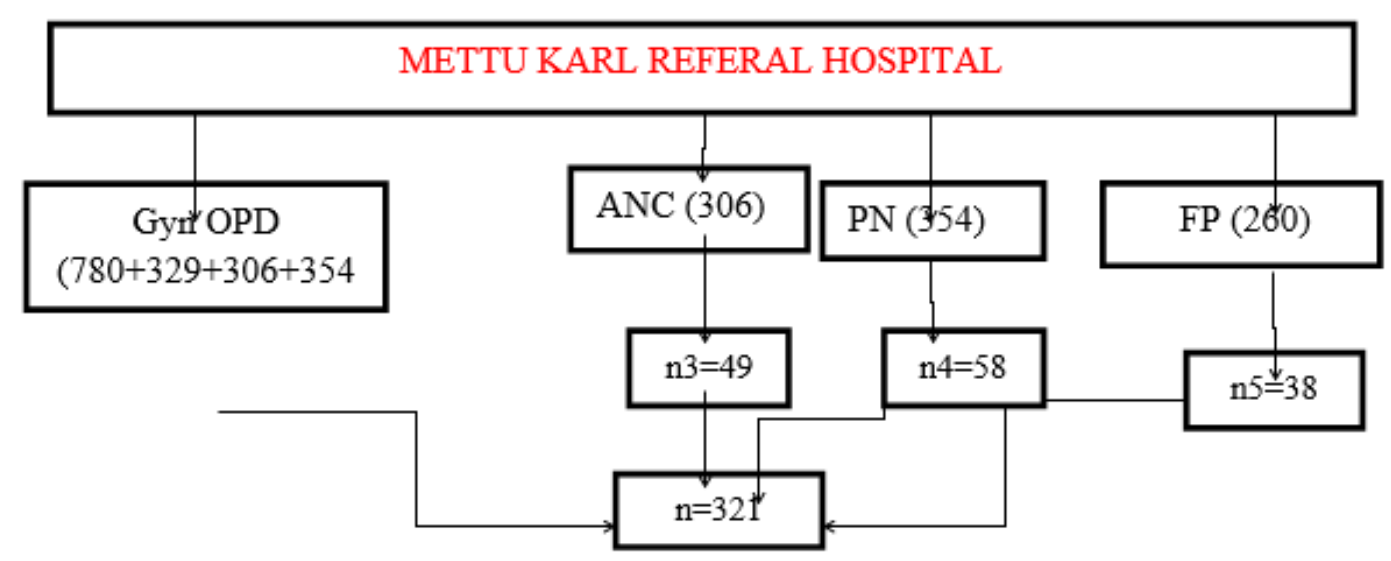

Figure 2

Sampling procedure on: Cervical cancer screening practiceand associated factors study.

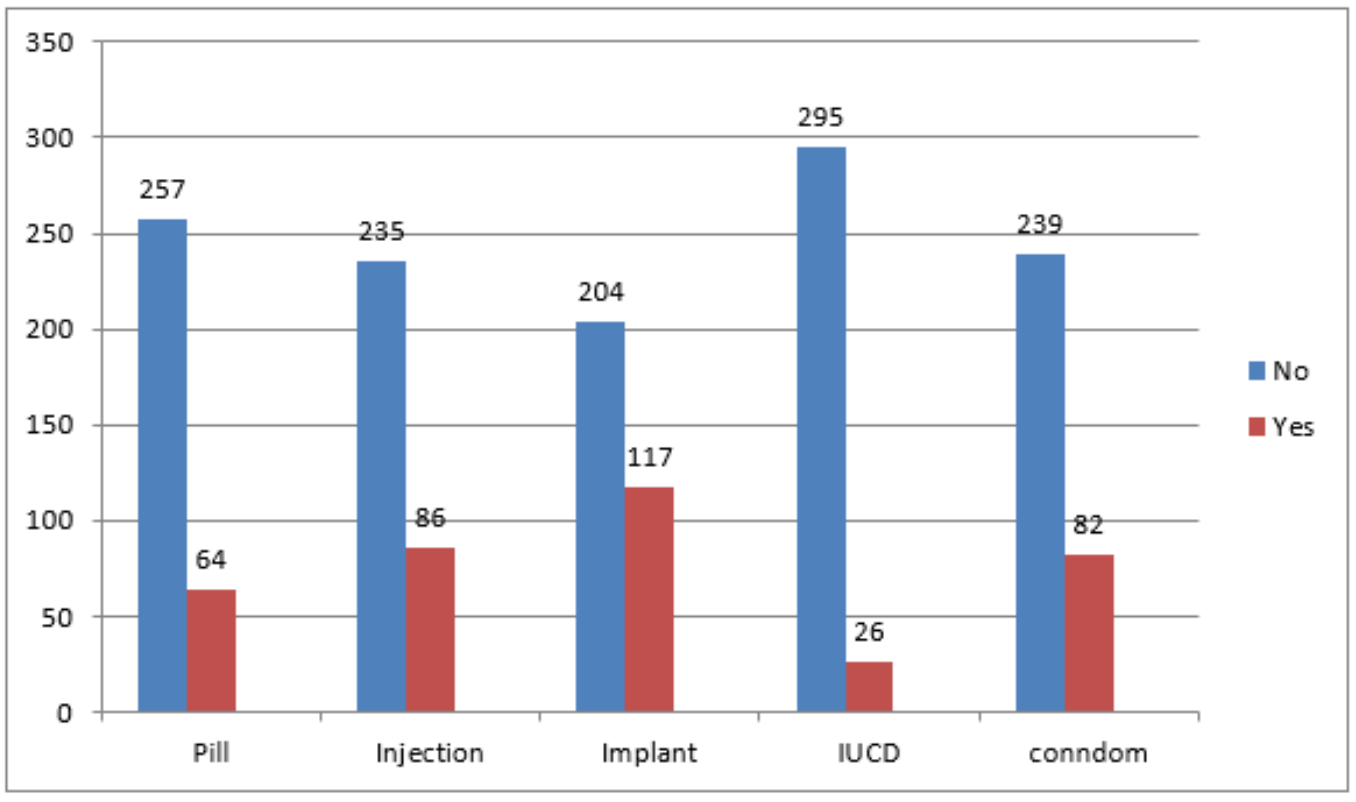

Figure 3

Description of women's contraceptive usage among women attending gynecology OPD and MCH at MK referral hospital, 2019 


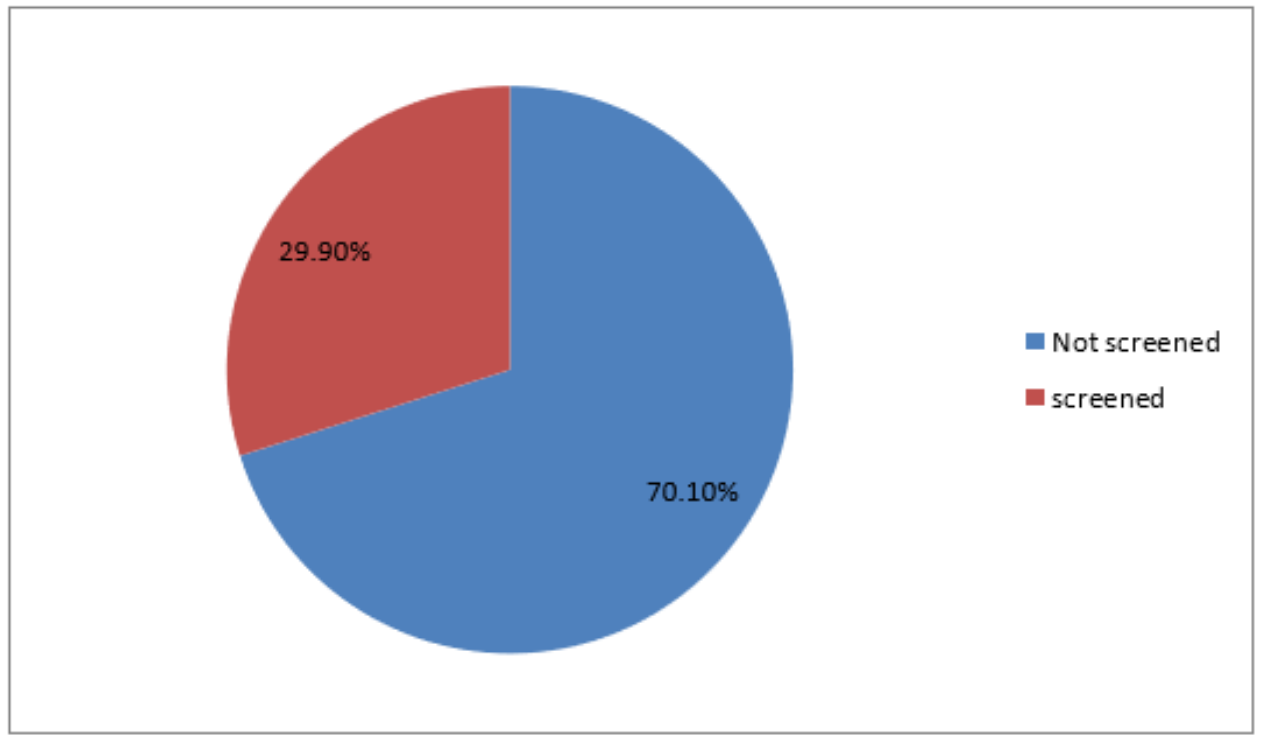

\section{Figure 4}

Intention to use cervical cancer screening practiceand barriers characteristics of women screened for cervical cancer 